\title{
Brasil entre o passado e o futuro: o que temos e o que queremos
}

\author{
Egeslaine de Nez ${ }^{1}$ \\ Odorico Ferreira Cardoso Neto ${ }^{2}$ \\ Warley Carlos de Souza ${ }^{3}$
}

\section{RESUMO}

Este artigo objetiva discutir o que sentimos falta com relação às mudanças no sistema educacional brasileiro, levando em conta os dados existentes nos últimos governos (Bolsonaro, Dilma e Lula), especificamente sobre a Educação Básica e Superior. Metodologidamente, é um ensaio teórico (pesquisa bibliográfica e documental) com abordagem de análise crítica. A justificativa para esse estudo são as políticas promovidas pelo governo atual que provocam, em nível nacional e internacional, um amplo debate na mídia e nas comunidades científicas. Além de uma possibilidade de refletir sobre o contexto da pandemia e as inseguranças geradas pela ausência de ações governamentais. O levantamento identifica que não há um sistema nacional que coordene as responsabilidades pela educação brasileira. Além disso, há extrema confusão no atual governo, falta investimento público, disputa de um projeto político-ideológico, entre outros fatores que impossibilitam a gestão da educação no país de forma democrática.

PALAVRAS-CHAVE: Sistema educacional brasileiro. Políticas públicas. Organização e gestão da educação.

Brazil between the past and the future: what we have and what we want

\begin{abstract}
This article aims to discuss what we miss about the changes in the Brazilian educational system, taking into account the data existing
\end{abstract}

\footnotetext{
${ }^{1}$ Pós-doutor em Educação. Universidade Federal de Mato Grosso (UFMT), Camus Universitário do Araguaia (CUA), Barra do Garças, Mato Grosso, Brasil. Orcid: http://orcid.org/0000-0002-0316-0080. E-mail: e.denez@yahoo.com.br. ${ }^{2}$ Possui pós-doutorado em Educação. Universidade Federal de Mato Grosso (UFMT), Campus Universitário do Araguaia (CUA), Barra do Garças, Mato Grosso, Brasil. Orcid: https://orcid.org/0000-0002-0104-2945. E-mail: kikoptbg@ gmail.com.

${ }^{3}$ Possui doutorado em Educação. Universidade Federal de Mato Grosso (UFMT), Campus Universitário do Araguaia (CUA), Barra do Garças, Mato Grosso, Brasil. Orcid: https://orcid.org/0000-0003-3057-2045. E-mail: warleycarlos@ @ahoo.com.br.
} 
in the last governments (Bolsonaro, Dilma and Lula), specifically about Basic and Higher Education. Methodologically, it is a theoretical essay (bibliographical and documentary research) with a critical analysis approach. The justification for this study is the policies promoted by the current government that provoke, at national and international level, a wide debate in the media and in the scientific communities. In addition to the possibility of reflecting on the context of the pandemic and the insecurities generated by the absence of government actions. The survey identifies that there is no national system that coordinates the responsibilities for Brazilian education. In addition, there is extreme confusion in the current government, lack of public investment, dispute over a politicalideological project, among other factors that make democratic education management in the country impossible.

KEYWORDS: Brazilian educational system. Public policy. Organization and management of education.

Brasil entre el pasado y el futuro: lo que tenemos y lo que queremos

\section{RESUMEN}

Este artículo tiene como objetivo discutir lo que extrañamos de los cambios en el sistema educativo brasileño, teniendo en cuenta los datos existentes en los últimos gobiernos (Bolsonaro, Dilma y Lula), específicamente sobre Educación Básica y Superior. Metodológicamente, es un ensayo teórico (investigación bibliográfica y documental) con enfoque de análisis crítico. La justificación de este estudio son las políticas impulsadas por el actual gobierno que provocan, a nivel nacional e internacional, un amplio debate en los medios de comunicación y en las comunidades científicas. Además de la posibilidad de reflexionar sobre el contexto de la pandemia y las inseguridades que genera la ausencia de acciones gubernamentales. La encuesta identifica que no existe un sistema nacional que coordine las responsabilidades de la educación brasileña. Además, existe extrema confusión en el actual gobierno, falta de inversión pública, disputa por un proyecto político-ideológico, entre otros factores que imposibilitan la gestión democrática de la educación en el país.

PALABRAS CLAVE: Sistema educativo brasileño. Políticas públicas. Organización y gestión de la educación. 


\section{Introdução}

O Brasil é um país que abrange uma infinidade de características geográficas, sociais e culturais. Mas, toda essa diversidade dificulta, de certo modo, o desenvolvimento de uma educação equânime ${ }^{4}$. Isso se torna um grande desafio, principalmente sem a construção de um sistema nacional que articule as diferentes realidades. No contexto geral, o país apresenta desigualdades tanto nos recursos disponíveis para as instituições de ensino quanto nos resultados de aprendizagem.

Embora o termo "sistema" seja de uso corrente em diferentes contextos dando a impressão de que se trata de algo previamente concebido que se pode identificar externamente, é preciso ter presente que não é um dado natural, ao contrário, é um produto da ação humana. Sistematizar é, dar unidade à multiplicidade. E o resultado obtido, é o que se chama "sistema". Segundo Saviani (2008, p. 3) se caracteriza como uma "unidade de vários elementos intencionalmente reunidos de modo a formar um conjunto coerente e operante".

Atualmente, não há um sistema nacional que coordene as responsabilidades pela educação brasileira, mas isso não significa que não exista ordenação legal para isso (TODOS PELA EDUCAÇÃO, 2020). Entre elas, a Constituição Federal (CF) de 1988, prevê uma lei complementar para garantir o estabelecimento desse sistema (BRASIL, 1988).

É importante esclarecer que o Sistema Nacional de Educação (SNE) não é a mesma coisa que um sistema educacional. Enquanto um sistema educacional diz respeito à organização do ensino no País (conteúdos, etapas de formação, entre outros elementos), o sistema nacional organiza as responsabilidades pela educação de todo o país. Ou seja, organiza e distribui as funções entre os

\footnotetext{
${ }^{4}$ Do latim aequanimus (aequi - igual, anime - ânimo) significa imparcialidade e igualdade. É aquilo que possui ou demonstra moderação, justiça, é a disposição de reconhecer igualmente o direito de cada um (DICIONÁRIO, 2020).
} 
municípios, estados e a união, e, como essas três esferas de governo devem trabalhar coletivamente (TODOS PELA EDUCAÇÃO, 2020).

Para Saviani (1999) o sistema é uma unidade de elementos reunidos, que estreita a relação entre sistema de educação e plano de educação. Deste modo, o SNE deve instituir os níveis de colaboração, o que pode ajustar e facilitar o tratamento das desigualdades existentes na educação brasileira. Além da CF, os principais documentos para se caracterizar um sistema são a Lei de Diretrizes e Bases da Educação (LDB) n. ${ }^{\circ}$ 9.394/1996; e o Plano Nacional de Educação (PNE) 2014-2024 que contribuem para estabelecer metas que devem ser atendidas durante o período de vigência (BRASIL, 2014).

Conjuntamente a essas leis, vários órgãos são responsáveis pelo funcionamento do sistema educacional brasileiro. Em nível federal: o Ministério da Educação (MEC) e o Conselho Nacional de Educação (CNE). No âmbito estadual, as Secretarias Estaduais de Educação (SEE) e os Conselhos Estaduais de Educação (CEE). E, no município, são as Secretarias Municipais de Educação (SME) e os Conselhos Municipais de Educação (CME).

A proposta desse texto é apresentar o que sentimos falta com relação às mudanças no sistema educacional brasileiro, levando em conta os dados existentes nos últimos governos (Bolsonaro, Dilma e Lula), especificamente no que tange a Educação Básica e Superior. Para isso, o procedimento metodológico utilizado foi uma pesquisa bibliográfica e documental com abordagem de análise crítico-reflexiva. Essa discussão se justifica, pois, as políticas promovidas pelo governo atual provocam, em nível nacional e internacional, um amplo debate na mídia e nas associações científicas.

Esse estudo aborda os dados relativos aos três últimos presidentes eleitos, para a compreensão dos processos constitutivos de um "sistema educacional brasileiro". Os governos de Lula e Dilma construíram de 2003 a 2016, o pressuposto de que a educação é bem público, "um direito subjetivo de todo cidadão, uma política pública de responsabilidade do Estado, estratégica e imprescindível para o novo projeto de desenvolvimento da nação" (MERCADANTE e ZERO, 2018. p. 24). Bolsonaro baseia-se no senso 
comum, pautando a educação brasileira em estratégias desenvolvidas em outros países, sem reconhecer a identidade nacional.

Para a compreensão desses elementos e a construção de uma reflexão robusta, o texto foi dividido em cinco partes, com a introdução e as considerações finais. Na parte que segue, apresentam-se alguns dados relativos ao que temos na Educação Básica; na terceira parte do artigo, o foco de luz é sobre a Educação Superior; a parte quatro considera as proposições para se pensar o que precisamos para um sistema que funcione na realidade brasileira.

\section{Brasil: o que temos na Educação Básica}

Os governos de Lula e Dilma investiram em educação como nunca na história recente e atingiram todas as etapas do ensino. $\mathrm{Na}$ concepção desses presidentes, a educação é um direito humano fundamental e um dos principais meios de acesso à cultura, além de ser instrumento de desenvolvimento econômico e social. Por isso, priorizaram os investimentos em educação, da creche à pós-graduação, por meio da adoção de uma série de políticas públicas integradas e articuladas (PARTIDO DOS TRABALHADORES, 2020).

O levantamento bibliográfico e documental realizado permitiu observar que para a Educação Infantil, primeira etapa na infância e de extrema relevância para o desenvolvimento da criança, o governo Lula retomou a colaboração com municípios para ampliação com qualidade das vagas em creches, além de fortalecer as políticas voltadas para a pré-escola (PARTIDO DOS TRABALHADORES, 2020).

As matrículas em creches $^{5}$ pularam de 1,23 milhão de matrículas, em 2003, para mais de 3,04 milhões em 2015 e o acesso à pré-escola foi praticamente universalizado. Sobre as matrículas na Educação Infantil ver informações no gráfico que segue:

\footnotetext{
${ }^{5} \mathrm{O}$ conceito de creche sofreu inúmeras transformações ao longo dos anos, chegando a uma definição legal na LDB 9.394/96: “A Educação Infantil, primeira etapa da Educação Básica, tem como finalidade o desenvolvimento integral da criança até seis anos de idade, em seus aspectos físico, psicológico, intelectual e social, complementando a ação da família e da comunidade" (Artigo 29). Deste modo, insere-se em definitivo a creche e a pré-escola na esfera educativa.
} 
Gráfico 1 - Quantitativo de crianças matriculadas na Educação Infantil

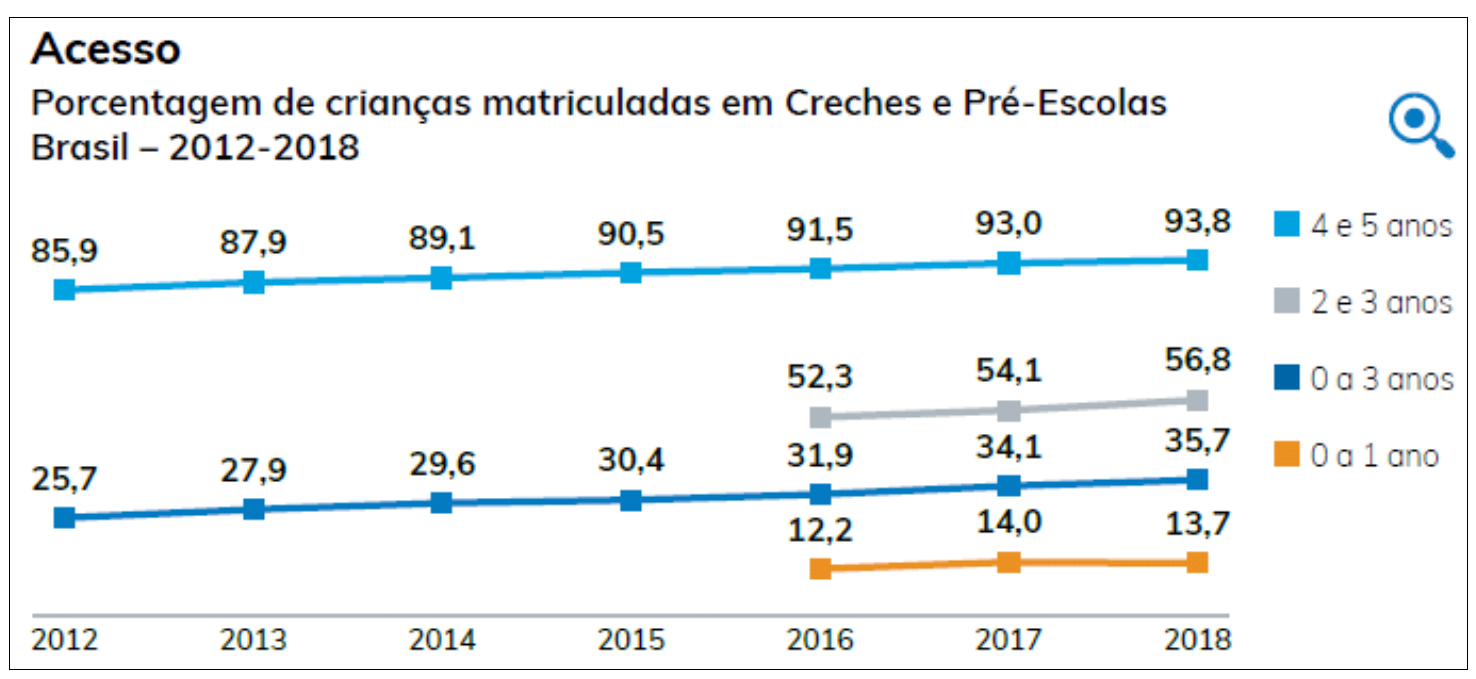

Fonte: Anuário Todos pela Educação (2020).

Os dados apontam que as matrículas na Educação Infantil cresceram $84,7 \%$, entre 2008 e 2016. Vale ressaltar que em 2012, a presidenta Dilma lançou o programa Brasil Carinhoso para apoio às creches que já existiam e a construção de novas com padrão arquitetônico e pedagógico. Foram concluídas e entregues 2.940 unidades até 2015; deixadas em andamento, com recursos orçamentários assegurados, outras 2.093; foram pactuadas com as prefeituras 3.167 novas creches. O governo que assumiu interinamente em $2016^{6}$ acabou com o programa e abandonou a política de apoio à Educação Infantil (MERCADANTE, e ZERO, 2018).

Segundo a análise do Todos Pela Educação em 2019, já no governo de Bolsonaro, o Brasil tinha 1.085 obras de creches e pré-escolas que não foram concluídas e o menor repasse de verbas desde 2009.

Tratando-se também sobre o Ensino Fundamental e Médio, especificamente com relação à taxa de atendimento, ver os dados que seguem nos gráficos 2 e 3.

\footnotetext{
6 Dilma deixou o segundo mandato na presidência após sofrer impeachment em meio a denúncias de corrupção e manobras fiscais. Por ocasião da interrupção, Temer assume a presidência interinamente por três meses e 19 dias, e, em definitivo, no dia 31 de agosto de 2016 (O NACIONAL, 2016).
} 
Gráfico 2 - Quantitativo de crianças e jovens matriculadas no Ensino Fundamental

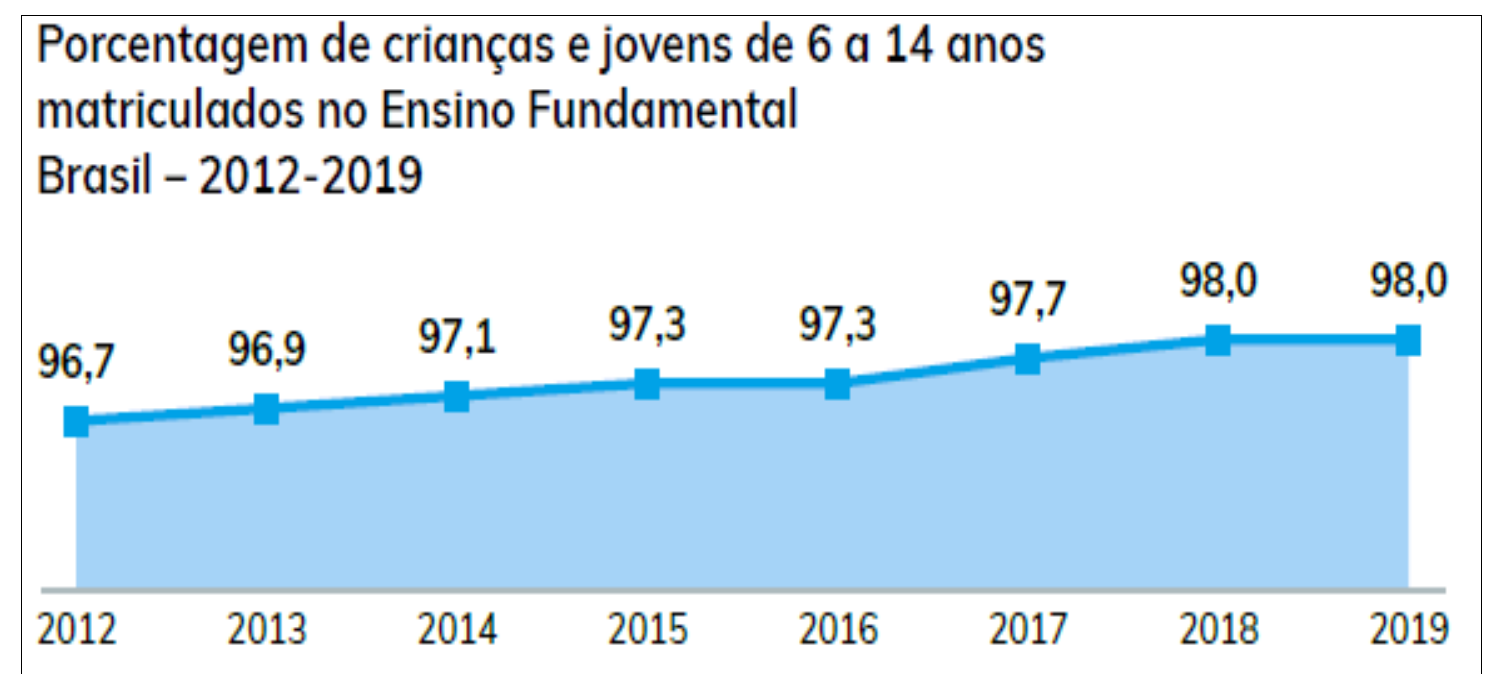

Fonte: Anuário Todos pela Educação (2020).

Gráfico 3 - Quantitativo de jovens matriculadas no Ensino Médio

\section{Porcentagem de jovens de 15 a 17 anos matriculados no Ensino Médio - Brasil - 2012-2019 \\ Taxa líquida de matrícula}

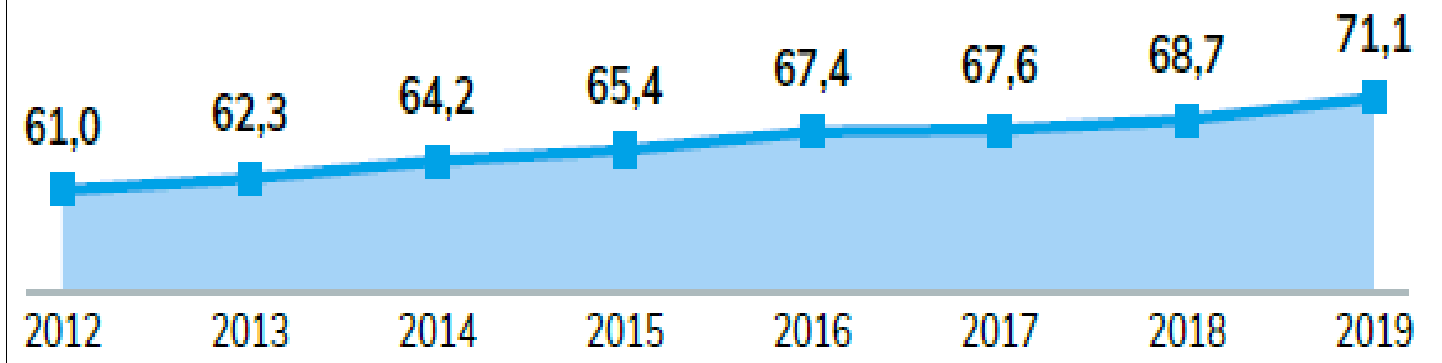

Fonte: Anuário Todos pela Educação (2020).

Lula demonstrou, por meio de seu governo, compromisso com todas as etapas e modalidades de educação. No país, aumentou o número de jovens que ingressaram no Ensino Fundamental e concluíram o Ensino Médio, 
cresceu o acesso a Educação Superior e os professores ganharam a instituição de um piso salarial7.

Além disso, houve ênfase no Programa Nacional de Formação de Professores (PARFOR), onde os professores se inscrevem em cursos correspondentes às disciplinas que ministram. Merece destaque também os investimentos na escola em tempo integral e no Programa Mais Educação (MERCADANTE e ZERO, 2018).

Uma iniciativa importante foi o processo democrático de construção, discussão e implamantação de uma nova Base Nacional Comum Curricular (BNCC), no início do segundo mandato de Dilma buscando um currículo flexível. Aguiar e Tuttman (2020, p. 71) expõem que:

Examinar a trajetória de construção da Base Nacional
Comum Curricular (BNCC) nos governos de Dilma
Rousseff (2011-2016) e de Michel Temer (2016-2018)
requer um resgate do contexto, dos projetos em disputa,
das discussões e das iniciativas governamentais atinentes
ao campo de currículo nos governos anteriores dos
presidentes Fernando Henrique Cardoso (FHC - 1995-
2003) e Luiz Inácio Lula da Silva (2003-2011).

Conforme é perceptível, no gráfico 3, no Ensino médio, as matrículas na faixa etária de 15 a 17 anos cresceram, o que significa que frequentam a escola $84,6 \%$ da população. Entre os $20 \%$ da população brasileira mais pobre (em 2002), apenas 31,6\% estavam na série esperada; e, em 2015, 60,2\% estavam nessa condição. Entre os 5\% mais carentes, aumentou em quatro vezes o número de adolescentes que acessaram a escola na idade certa.

Mercadante e Zero (2018) informam que o Programa Nacional de Acesso ao Ensino Técnico e Emprego (PRONATEC), implantado por Dilma, a partir de 2011, foi um dos maiores programa de Educação Técnica e Profissionalizante da história do país. Ofertou 9,4 milhões de vagas, de

\footnotetext{
7 Implantado por Lula permitiu um crescimento real dos salários na Educação Básica de aproximadamente 49\%, entre 2009 e 2015. Os investimentos na formação inicial e continuada dos professores realizados por meio da criação do Pacto Nacional pela Alfabetização na Idade Certa (2012), no governo Dilma assegurou bolsa de estudos e um programa especial de formação para cerca de 300 mil professores alfabetizadores (TODOS PELA EDUCAÇÃO, 2020 e MERCADANTE e ZERO, 2018).
} 
modo a estimular a inclusão produtiva e abrir novas possibilidades no mercado de trabalho, gerando qualificação profissional.

Em linhas gerais, o presidente deixou explícito no seu plano de governo e durante o seu primeiro ano de mandato, uma ênfase no treinamento dos estudantes da Educação Básica para a realização das avaliações em larga escala e um Ensino Médio voltado para a formação de mão de obra por meio dos cursos profissionalizantes.

Bolsonaro anunciou no final de setembro que vai cortar recursos de áreas como educação, saúde, entre outras. O financiamento de serviços de atendimento à população carente é realizado com parte dos recursos de entidades do Sistema S. O corte vai promover queda da alíquota média, que passaria de 2,5\% para 1,5\%. O Serviço Nacional de Aprendizagem Industrial (SENAI) atua por meio de cursos profissionalizantes e o Serviço Social do Comércio (SESC) possui escolas, teatros, serviços de saúde, clubes esportivos, prêmios de incentivo à cultura e eventos artísticos e culturais. Essa ação governamental tende a prejudicar a população ${ }^{8}$.

\section{Brasil: o que temos na Educação Superior}

As transformações sociais, econômicas, políticas e culturais foram amplas nesses governos populares, tanto que que o Brasil nem teve muitas condições para extrair análises e projeções consistentes depois da saída "apressada" e "induzida" de Dilma da presidência da república. Sader e Garcia (2010) revelam que o país era um dos mais injustos do mundo e foi levado a uma categoria de menor desigualdades, projetando-o, à época, para se constituir na quinta maior economia do planeta.

Sobre a rede de universidades federais nos governos do Partido dos Trabalhadores (PT), houve a maior expansão de sua história. Era composta, em 2002, por 45 universidades com 148 campi, e, atingiu em 2015, 65

\footnotetext{
${ }^{8}$ Disponível em: https://www.bancariosbahia.org.br/noticia/29737,governo-quer-reduzir-os-recursos-dosistema-s.html. Acesso em: 05 out. 2020.
} 
universidades com 327 campi. Mercadante e Zero (2018) informam que foram criadas nos mandatos de Lula e Dilma um total de 18 universidades, 173 campi e centenas de unidades dos Institutos Federais de Educação (IFES).

No final do governo Dilma, já eram 38 IFES distribuídos em 600 campi. As matrículas dobraram, de 558 mil estudantes em 2002, para mais de 1 milhão em 2015. Toda essa expansão promoveu a inclusão de uma parcela da população historicamente excluída. $\mathrm{O}$ acesso ocorreu com maior ênfase por meio do Exame Nacional do Ensino Médio (ENEM) em 2009 no governo Lula (BRASIL, 2019).

Para ampliar o acesso à Educação Superior foram empreendidas, nesse período, várias ações, entre elas: manutenção do Programa de Apoio a Planos de Reestruturação e Expansão das Universidades Federais (REUNI) ${ }^{9}$; reestruturação do Programa Universidade para Todos $\left(\right.$ PROUNI) ${ }^{10}$ e o Programa de Financiamento Estudantil (Fies) ${ }^{11}$.

A lei de Cotas ( $\left.n^{0} 12.711 / 2012\right)$ também incrementou a democratização da Educação Superior, enfrentando a desigualdade social e a discriminação racial, buscando assegurar políticas de acesso aos estudantes da escola pública de baixa renda, negros e indígenas. As políticas de financiamento da Educação Superior fortaleceram a expansão de oportunidades, o Sistema de Seleção Unificada (SISU) incluíu e ampliou a oportunidade de milhões de jovens (BRASIL, 2019).

A partir desse conjunto de medidas, é possível inferir que $35 \%$ dos concluintes que fizeram o Exame Nacional de Desempenho dos Estudantes (ENADE), em 2015, foram os primeiros de suas famílias a serem diplomados. Mercadante e Zero (2018) confirmam a presença de jovens negros nesse processo. No que toca à formação de professores, a Universidade Aberta do Brasil (UaB) ofereceu ensino a distância e gratuito

\footnotetext{
9 Instituído pelo Decreto Presidencial $\mathrm{n}^{\circ}$ 6.096, de 24 de abril de 2007, com o objetivo de dar às instituições condições de expandir o acesso e garantir condições de permanência no Ensino Superior (MINISTÉRIO DA EDUCAÇÃO, 2020).

${ }^{10}$ É um programa que oferece bolsas de estudo, integrais e parciais (50\%), em instituições particulares de educação superior no país (PROUNI, 2020).

${ }^{11}$ Programa do MEC destinado a financiar a graduação de estudantes matriculados em cursos superiores não gratuitas na forma da Lei n ${ }^{\circ}$ 10.260/2001 (FIES, 2020).
} 
para os docentes da rede e foi constituído o Programa Institucional de Bolsas de Iniciação à Docência (PIBID) ${ }^{12}$.

Nos gráficos que seguem é possível observar o avanço nas matrículas nos últimos 10 anos, por categoria administrativa (universidades federais, estaduais e municipais) e os dados dos concluintes que possibilitam uma reflexão sobre a ênfase dada à Educação Superior nos governos Lula e Dilma.

Gráfico 4 - Matrículas em curso de graduação na rede pública (2008/2018)

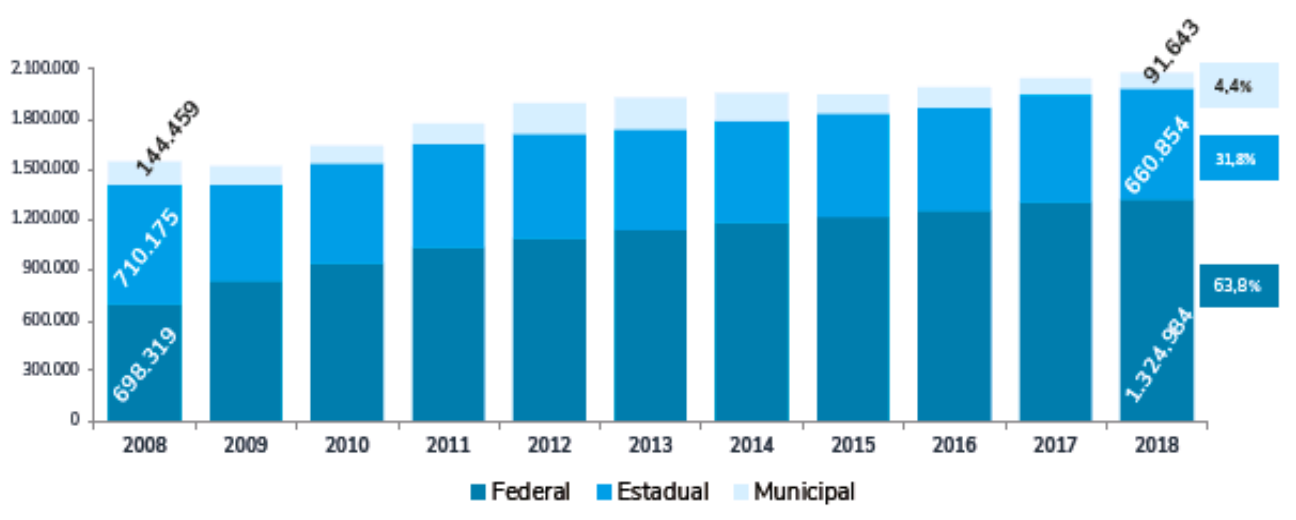

Fonte: Censo da Educação Superior (2018).

Gráfico 4 - Matrículas em curso de graduação na rede pública (2008/2018)

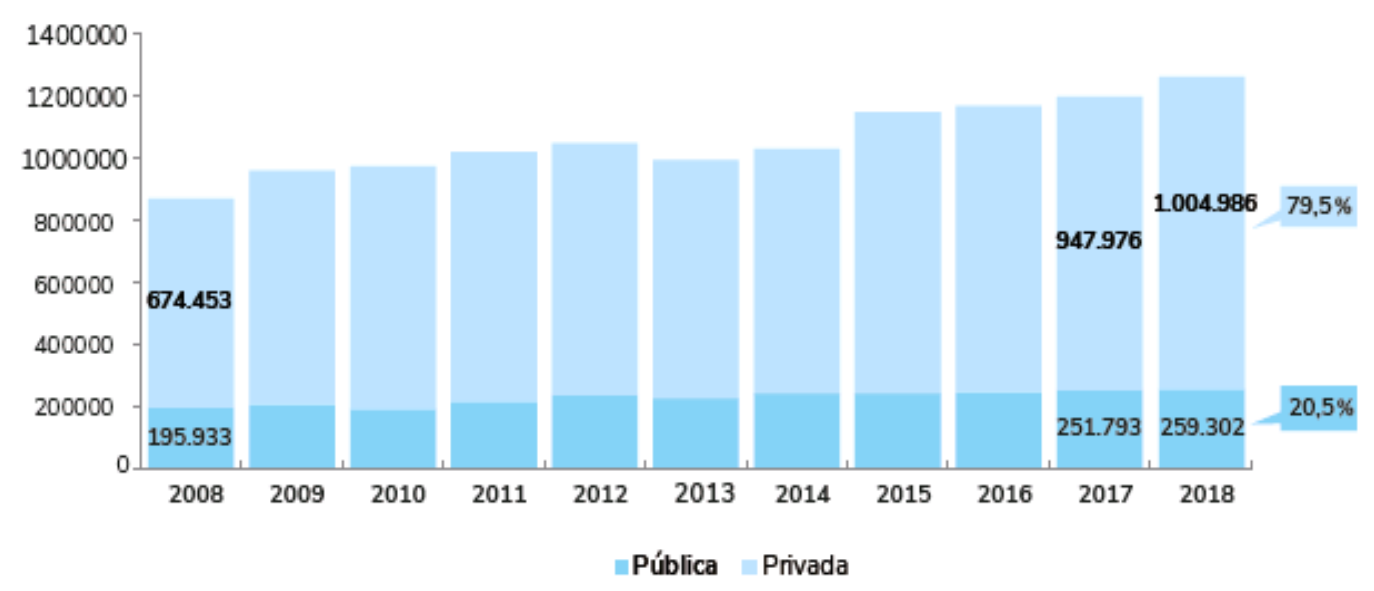

Fonte: Censo da Educação Superior (2018).

\footnotetext{
12 Uma das ações da Política Nacional de Formação de Professores do MEC que visa proporcionar aos discentes na primeira metade dos cursos de licenciatura, uma aproximação com o cotidiano das escolas de Educação Básica. No final de 2017, já no Governo Temer, encaminha-se o Programa de Residência Pedagógica e uma reestruturação no PIBID, que começa a ser implementado em 2018 (SOUZA e NEZ, 2020).
} 
Vale ressaltar nesse contexto que o Programa Ciência sem Fronteiras ${ }^{13}$ criado no início do governo Dilma, atuou como um avanço na mobilidade internacional estudantil e no fomento da internacionalização, levando cerca de 100 mil estudantes e pesquisadores brasileiros às universidades e centros de pesquisa, em 54 países. Os investimentos em educação, ciência, tecnologia e inovação também cresceram expressivamente nos governos do PT (MERCADANTE e ZERO, 2018).

Outro programa proposto pela Coordenação de Aperfeiçoamento de Pessoal de Ensino Superior (CAPES), em 2017, foi o Mais Ciência Mais Desenvolvimento que objetivava integrar ações referentes à internacionalização dos programas de pós-graduação, contudo, teve curta duração. Logo em seguida, no mesmo ano, foi substituído pelo Programa Institucional de Internacionalização (PRInt) que buscava fomentar a construção, a implementação e a consolidação de planos estratégicos de internacionalização das IES nas áreas do conhecimento priorizadas (NEZ e MOROSINI, 2020).

No governo do atual presidente, por causa do avanço desenfreado do coronavírus, a CAPES informou oficialmente que estariam suspensas todas as ações de mobilidade do PrInt agendadas para o ano de 2020. Nesse contexto, foi impossível executar as ações. Países limitaram a locomoção interna dos cidadãos que impactou nos docentes que já estavam fora do Brasil. Estes ficaram desorientados em função de uma brutal mudança de comportamento frente à pandemia, imobilizados nos países destino e sem conseguir executar o planejamento. Os semestres letivos foram sobreestados e instalou-se a incapacidade de implementar os projetos e missões de pesquisa que deveriam ser desenvolvidos (NEZ e MOROSINI, 2020).

\footnotetext{
${ }^{13}$ Lançado em 2011, e se constituía num programa de intercâmbio, em parceria com o governo federal e empresas privadas. Seu objetivo era estimular o avanço da ciência nacional em tecnologia, inovação e competitividade, por meio da mobilidade. Também buscava incrementar o quantitativo de pesquisadores e acadêmicos em instituições de excelência no exterior, assim como atrair pesquisadores para trabalhar no Brasil, por meio de incentivo financeiro (BRASIL, 2015).
} 
Por fim, é preciso relembar que o papel da universidade pública frente a Emenda Constitucional 95 (EC 95) aprovada pelo governo Temer (2016), que instituiu um Novo Regime Fiscal (NRF) no país com o congelamento de gastos, já tinha inviabilizado as políticas públicas educacionais tanto na Educação Básica quanto na Superior, colocando em risco a universidade e a existência da pesquisa (BORSSOI e NEZ, 2019). O modelo de pesquisa defendido pelo governo Bolsonaro é a pesquisa aplicada, pois considera que o campo da ciência e do conhecimento nunca deve ser estéril. Também prioriza algumas áreas em detrimento de outras e vem intensificando parcerias com a iniciativa privada e a tendência ao endurecimento do controle ideológico de estudantes e de professores.

Bolsonaro baseia-se no senso comum, desconsidera inúmeras pesquisas e estatísticas, pauta a educação brasileira nas estratégias desenvolvidas no Japão, Taiwan e Coréia do Sul. Todavia, passado vinte meses de governo, nada foi articulado para a Educação, apenas seu desmonte financeiro. $\mathrm{O}$ que se implementou ao longo desse período inicial de governo instiga a intolerância ao marxismo, Paulo Freire, a discussão de gênero na escola e outros elementos controversos.

\section{Brasil: o que queremos}

A estruturação na educação na contemporaneidade se manifesta numa relação dialética, a saber, ora caminha na direção da utopia ${ }^{14}$, com potencialidade de transformação da realidade de proporcionar formação humana a todos indiferentemente de classe social, cor, gênero e sexo.

Por outro lado, a mesma educação se manifesta com desencanto, em função do distanciamento da formação humana e sua impotência em lidar com a realidade objetiva dos dados apresentados ao longo deste estudo. A educação sistematizada se caracteriza por uma contradição, pois, existem

\footnotetext{
${ }^{14}$ A utopia nesse caso possue sentido positivo quando defende que esse ideal contém o germe do processo social e da transformação da sociedade (JAPIASSU e MARCONDES, 2001).
} 
aqueles que defendem a lógica dos estratos sociais mais altos (donos do capital); esses por sua vez, defendem a formação de mão-de-obra que atenda ao mercado e, assim, ofertar educação que se baseiei na técnica.

$\mathrm{Na}$ direção oposta, estão os que defendem que o produzido na sociedade e pela sociedade pertence a todos, assim, a técnica voltada para o mercado de trabalho seria apenas uma das diferentes linhas de atuação da escola. Dessa forma, não ensinaria somente a "letra morta", mas como a vida é produzida por meio da literatura, nas diferentes manifestações da arte, isso para não mencionar o básico, que é o ensino das ciências.

Pautando-se na educação como um direito humano fundamental e um dos principais meios de acesso à cultura, o sujeito ao passar pela escola deveria ser capaz de ler o mundo em diferentes óticas, o que representa a possibilidade de compreender as formas de sentir, pensar e agir no mundo.

O nascimento de uma criança representa a clara necessidade de construção de um novo mundo, com outras possibilidades de reinventar o sentir, o pensar e o agir sobre a realidade. No entanto, quando se insiste em uma educação eminentemente técnica, sem nenhuma transformação social, gera-se uma legião de analfabetos culturais.

Fato esse que gera pré-conceitos, preconceitos, em função de grupos que acreditam que sua cultura é superior a de outros, isso garante a sustentação das diferentes manifestações de violência. Diante disso, compreende-se que o investimento em educação é muito maior que o financeiro, deve ser na formação humana para alunos e professores.

Isso comprova que a formação humana passa sumariamente pelo olfato, pela motricidade, pela visão, embora essas dimensões sejam do ponto de vista biológico característica da espécie, defende-se que são desenvolvidas na e pela cultura e não somente pela dimensão neurofisiológica como pontua uma visão técnica da educação. Portanto, a escola para possuir qualidade social necessita ser organizada para apresentar essas dimensões aos educandos e professores. 
Diante disso, a formação humana de qualidade social, aqui defendida e já anunciada, pressupõe não apenas uma formação técnica, aqui compreendida como cursos burocráticos que ensinam/adestram os professores a usarem a máquina burocrática do estado. Mas, por outro lado, que essa formação fundamente a erudição do corpo docente na direção de apresentar ao aluno ao mundo erudito. Essa questão é esclarecida por Souza (2017):

Como os estímulos à leitura e à imaginação são menores aos pobres possuem quase sempre enormes dificuldades de se concentrar na escola. Muitos relatam em entrevistas que fitavam o quadro negro por horas sem conseguir aprender o conteúdo. A capacidade de concentração não é, portanto, um dado natural como ter dois ouvidos e uma boca e, sim, uma habilidade e disposição para o comportamento aprendida apenas quando adequadamente estimulada (p. 98).

Assim sendo, não se nasce pronto a aprender, ao contrário disso, é imprescindível um adulto/professor para ensinar a concentração, para interagir com o conhecimento organizado e sistematizado na instituição educacional. Isso signifca dizer que, de nada adianta um percentual quantitativo de crianças e jovens matriculadas no Ensino Fundamental e Médio, se não houver essa relação entre o aluno e o professor. Garantir o acesso, é importante, porém, a permanência deve ser garantida com ênfase nas políticas e programas que visam garantir essa educação de qualidade social nas escolas públicas.

Nas duas últimas décadas, as políticas públicas, resultantes dos governos indicados e da correlação de forças das quais merece destaque as demandas na/da sociedade civil e dos movimentos sociais, houve um processo de democratização do direito de acesso à Educação Básica.

Conforme Souza (2017) expõem há quem a receba de "berço" e se torna um privilegiado.

É assim que se formam os privilégios tipicamente da classe média para que seu monopólio sobre o conhecimento valorizado seja mantido através de gerações. Para o filho já adulto, com emprego e bem pago e com prestígio social, 
tudo é percebido como se fosse um milagre do mérito individual (SOUZA, 2017, p. 98).

Objetivamente, a universidade não deveria esperar um "milagre" na formação de professores das diferentes licenciaturas; e, por sua vez, os acadêmicos ao se tornarem responsáveis por uma sala de aula não podem esperar um "milagre" do sistema educacional; ambos deveriam possibilitar fazer o prodígio. Assim, a formação continuada é:

[...] um processo complexo e multideterminado, que ganha materialidade em múltiplos espaços/atividades, não se restringindo a cursos e/ ou treinamentos, e que favorece a apropriação de conhecimentos, estimula a busca de outros saberes e introduz uma fecunda inquietação contínua com o já conhecido, motivando viver a docência em toda a sua imponderabilidade, surpresa, criação e dialética com o novo (PLACCO; SILVA, 2009, p. 27).

O PIBID é um deses momentos que pode provocar reflexões nos licenciandos e transformações na realidade escolar. Gatti et al (2014, p. 5) explicita que os acadêmicos das licenciaturas exercem atividades nas escolas públicas de Educação Básica, “[...] contribuindo para a integração entre teoria e prática, para aproximação entre Universidade e escolas e para a melhoria de qualidade da educação brasileira".

É evidente que essa proposição precisa romper com o modelo de treinamento de alunos e professores, a escola precisa de aprendizagens que proporcionem a apropriação do mundo de maneira humana. Assim, o PIBID e, posteriormente o Residência Pedagógica, enquanto programas de formação de professores, corroboram na interlocução da universidade com a escola. Respondendo ao objetivo principal desse estudo, sente-se falta, então, de políticas de continuidade dessas ações que constituem a sistematização de uma política de estado que tenha caráter permanente.

Ainda sobre o que é ausente ou inexistente no sistema educacional brasileiro, cabe refletir sobre os sentidos da democracia nas relações escolares. A democracia não pode ser para simples contemplação, deve ser 
pensada de forma ativa e responsável numa relação intrínseca entre homem e natureza, negando o hiper individualismo apregoado no atual momento histórico. A partir disso, só é possível pensar a educação de modo coletivo,

De qualquer maneira a propriedade privada é somente a expressão sensível do fato de que o homem se torna objetivo para si e, ao mesmo tempo, converte-se melhor num objeto estranho e desumano, o fato de que sua exteriorização vital é sua alienação vital, sua realização é sua desrealização, uma realidade estranha, a superação da propriedade privada, isto é, apropriação sensível por e pelo homem da essência e sentido do gozo imediato, exclusivo, no sentido da possessão, do ter. O homem apropria sua essência universal de forma universal, isto é, como homem total. Cada uma das suas relações humanas com o mundo (ver, ouvir, cheirar, degustar, sentir, pensar, observar, perceber, desejar, atuar, amar), em resumo, todos os órgãos de sua individualidade, como os órgãos que são imediatamente comunitários em sua forma, são, em seu comportamento objetivo, em seu comportamento desde o objeto, a apropriação deste. A apropriação da realidade humana, seu comportamento desde o objeto, é a afirmação da realidade humana, é a eficácia humana e o sofrimento humano, pois o sofrimento, humanamente entendido, é um gozo do próprio homem (MARX e ENGEL, 2004, p. 41).

Em razão disso, o sistema educacional brasileiro deve ser organizado para garantia que o ser humano se desenvolva humanamente, e isso, somente ocorre na presença de iguais de direitos. Destarte, o conhecimento escolar não pode tirar do aluno e do professor sua humanidade.

A educação é a oportunidade de compartilhar o mundo, portanto é a oportunidade de se negar um projeto de sociedade que faça apologia à modernidade hegemônica e que se sustente na individualidade para efetivar uma proposta de educação baseada no público, no universal e, numa democracia que possa libertar.

Para Santos (1999), o projeto de sociedade de uma modernidade hegemônica faz parecer que o mundo politico chegou ao seu fim, tudo parece indicar que na verdade, com a perda do direito humano, o próprio sujeito de direito entrou em crise, o que leva a um individualismo indomado. Isso 
privatiza as relações humanas, o que dá a educação formal outro modelo que exclui sumariamente os mais frágeis, a grande maioria da população.

A subjetivação dos direitos e como consequência na formação humana (educação), retira do centro dessas relações o homem concreto, que objetiva a substituição por um ser abstrato, que dá seu próprio sentido à construção da sua humanidade. Como consequência, tem-se:

A obliteração intelectual dos adolescentes, artificialmente produzida com a transformação deles em simples máquinas de fabricar mais-valia, é bem diversa daquela ignorância natural em que o espírito, embora sem cultura, não perde sua capacidade de desenvolvimento, sua fertilidade natural (MARX e ENGEL, 2004, p.69).

Isso leva a reflexão que para a efetivação de um projeto de educação centrado no humano, há necessariamente que ter um Estado que administre com e para a população e, não que em alguns momentos o governo pense no estrato superior da pirâmide social, nos donos do capital. E que em outros momentos, tem-se um governo que administre para o estrato da base, o trabalhador, essa relação polarizada tenciona as relações sociais que ora tende para um lado, ora para outro. $\mathrm{Na}$ Educação Superior, o FIES, o SISU, a lei de cotas, entre outras ações é a demonstração do governo administrar para o trabalhador. Em contrapartida, há outras situações que fica nítido as proposições apenas para os donos de meios de produção.

Como consequência não se protegem os os mais frágeis da sociedade dessa relação destrutiva, tal proteção só pode ser dada com a manutenção de um Estado forte que garanta efetiva formação humana a todos. Definitivamente, é disso que se sente falta quando se pensa em programas e políticas de implementação do sistema educacional. Em contrapartida, no governo atual há falta de financiamento, ausência de políticas, entre outros fatores impeditivos de qualquer tipo de formação. 


\section{Conclusão}

Levando-se em conta o objetivo proposto nesse ensaio teórico, é possível constatar que o sistema educacional brasileiro é um híbrido de avanços e recuos. Os recuos historicamente adulteraram a capacidade dos organismos responsáveis em nível municpal, estadual e federal de produzirem políticas de Estado e não, apenas, políticas de governo.

Os dados levantados identificam que de 2003 a 2016, aconteceram avanços significativos, entretanto, com o golpe jurídico midiático, que derrubou o governo Dilma, assendeu ao poder um misto indigesto de um nazifascismo que colocou a "terra redonda" em transe.

Esse estudo buscou pensar do que se sente falta com relação às mudanças no sistema educacional brasileiro. Há ausência do SNE que foi enunciado na meta 20 do PNE, em sua estratégia 20.9 que deveria articular o sistema nacional de educação em regime de colaboração. Todavia, passados quase quatro anos o que sobra são retrocessos.

Outro ponto de avanço mas que tendencialmente pode virar ao longo do tempo um retrocesso é a aprovação em agosto de 2020 do Fundo Nacional de Desenvolvimento da Educação Básica (Fundeb). É um marco importante, tendo em vista que foi uma derrota sem precedentes na história republicana em que o governo de não pretendia ter o fundo aprovado como lei. O novo Fundeb é o principal mecanismo de financiamento da Educação Básica pública no Brasil. O grande desafio para não cair no esquecimento e inexistência será elaborar uma lei complementar que regulamente o fundo.

Do ponto de vista da governança, tem-se nesse momento histórico, pandêmico, mais recuos do que avanços. Do ponto de vista da estruturação da Educação Básica e Superior, a relação dialética, espaço da utopia, com potencialidade de transformação da formação humana a todos indiferentemente de classe social, cor, gênero, sexo, está agravada pela falta de sensibilidade com o mais elementar respeito ao contrato social da 
convivência - o respeito ao outro. A imagem a seguir sintetiza os anseios em relação ao sistema educacional brasileiro

Imagem 1 - O sistema educacional brasileiro que queremos

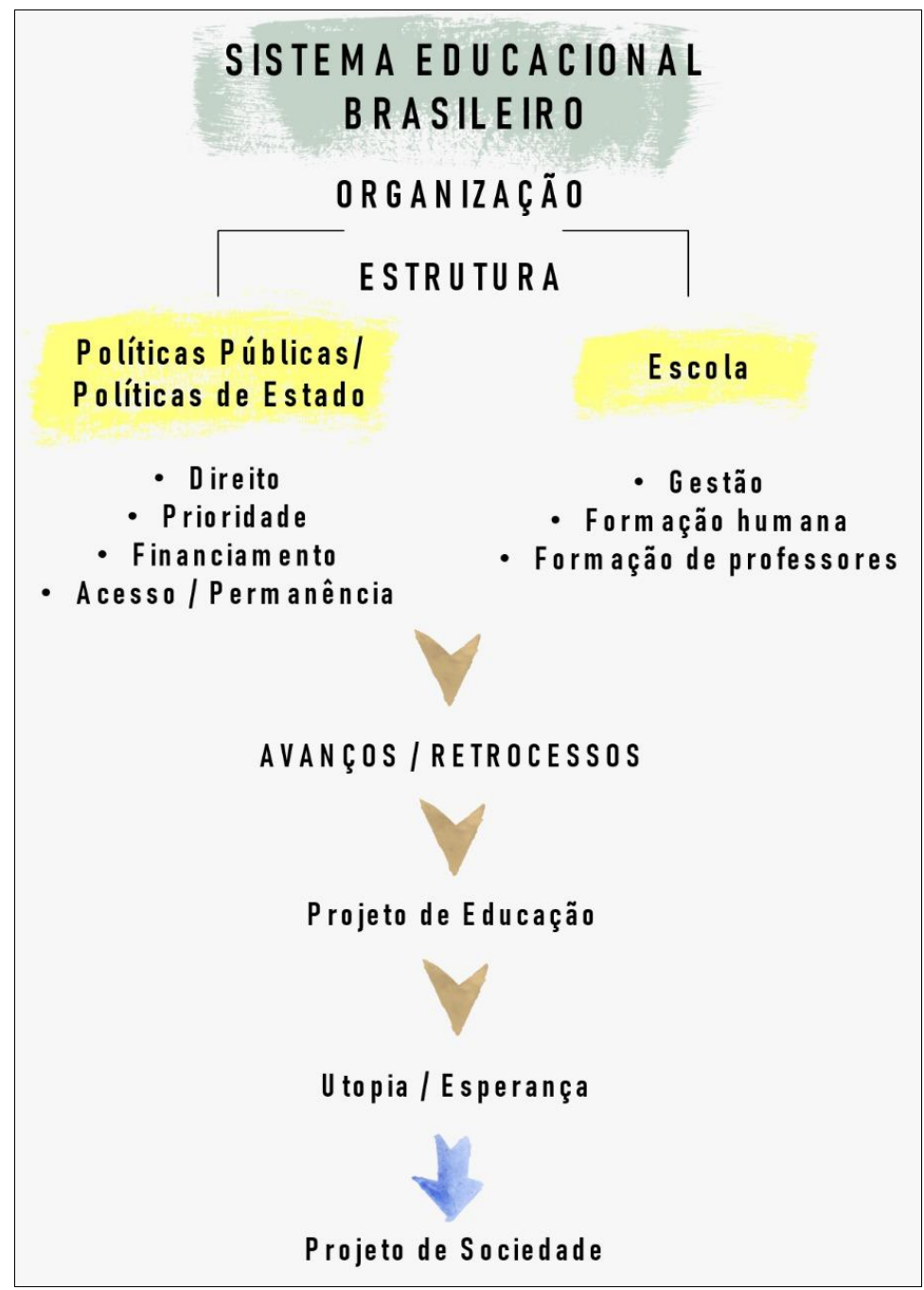

Fonte: Os autores (2020).

Finalmente do que se sente falta com relação às mudanças no sistema educacional brasileiro? Falta investir em políticas públicas que institucionalizem atos concretos a favor daqueles que se encontram abaixo da linha da pobreza. Estas precisam gerar renda, emprego, maior participação dos menos favorecidos no mercado de trabalho, ações de curto, médio e longo prazo que aumentem a escolaridade dos menos favorecidos em todos os níveis.

É preciso recuperar o percurso das políticas públicas geradoras de inclusão social, roteiros que planejem, deliberem e criem um conjunto de 
atividades voltadas para o desenvolvimento social e educacional das famílias carentes. Mais do que nunca, a realidade mostra a "olhos nus" o processo de invisibilidade imposto aos que vivem abaixo da linha da pobreza.

O cenário mais visível para auditar a realidade refletida parece ser a educação, tendo em vista ser o direito inalienável que mais atende a população cotidianamente. Todos os dias mais de 50 milhões de crianças e jovens são atendidas nas escolas.

Qual é, então, a esperança? Interagir, conectar-se, dialogar, propor, fazer pensar de forma comprometida a formação humana de modo não alienado, dizendo não ao neoliberalismo, ao fascismo e a quaisquer formas de extremismos.

Avançar para o futuro pensando que o "novo anormal" proporcionado pela COVID-19 tornem as lideranças governamentais mais humanas. É fundamental ter esperança que nutre sonhos, realidades de um outro tempo, de um novo anúncio de autonomia e de resiliência.

Esse texto não apenas mostra a herança recebida do passado e as transformações realizadas como também aponta o caminho a trilhar para fazer deste um país realmente democrático, solidário e soberano. Por isso, deve-se avançar nesse gigante Brasil.

\section{Referências}

AGUIAR, M. A. da S.; TUTTMAN, M. T. Políticas educacionais no Brasil e a Base Nacional Comum Curricular: disputas de projetos. Em Aberto, Brasília, v. 33, n. 107, p. 69-94, jan./abr. 2020. Disponível em: file:///C:/Users/HP/Downloads/4556-Texto\%20do\%20artigo-5322-1-1020200730.pdf. Acesso em: 04 out. 2020.

ANUÁRIO todos pela educação. Disponível em:

https://www.todospelaeducacao.org.br/conteudo/anuario-2020-Todos-PelaEducacao-e-Editora-Moderna-lancam-publicacao-com-dados-fundamentaispara-monitorar-o-ensino-brasileiro/. Acesso em: 01 ago. 2020.

BORSSOI, B. L.; NEZ, E. A universidade pública e a emenda constitucional 95/2016: qual será o futuro da pesquisa? In: Política e Gestão da Educação Superior. Brasília: Anpae, 2019. 
BRASIL. Constituição da república federativa do Brasil 1988. São Paulo: Saraiva, 2007.

BRASIL. Lei n. 13.005, de 25 de junho de 2014. Aprova o Plano Nacional de Educação (PNE). Brasília. Disponível em:

http://www.planalto.gov.br/ccivil_03/_Ato2011-2014/2014/Lei/L13005.htm. Acesso em: 01 jun. 2015.

BRASIL. Lei n. 9.394 de 20 de dezembro de 1996. Disponível em: http://www.planalto.gov.br/ccivil_03/Leis/L9394.htm. Acesso em: 22 mar. 2009.

BRASIL. Programa ciência sem fronteiras. Disponível em: http://www.cienciasemfronteiras.gov.br/web/csf. Acesso em: 26 set. 2015.

BRASIL. 2003 a 2010: biblioteca da presidência - planalto. Disponível em: https://www.gov.br/planalto/pt-br/conheca-a-presidencia/acervo/bibliotecada-presidencia. Acesso em: 10 dez. 2019.

CENSO da Educação Superior 2018. Disponível em:

http://portal.inep.gov.br/web/guest/educacao-superior. Acesso em: 8 maio 2020.

DICIONÁRIO de significados. Disponível em:

https://www.significados.com.br/equanime/\#: :text=O $\% 20$ que $\% 20 \% \mathrm{C} 3 \% \mathrm{~A} 9 \%$ 20Equ\%C3\%A2nime $\% 3 \mathrm{~A}$,igual $\% 2 \mathrm{C} \% 20$ anime $\% 20 \% 2 \mathrm{D} \% 20 \% \mathrm{C} 3 \% \mathrm{~A} 2$ nimo. Acesso em: 21 set. 2020.

FIES. Disponível em: http://sisfiesportal.mec.gov.br/?pagina=fies. Acesso em: 05 ou. 2020.

GATTI, B. A.; et al. Um estudo avaliativo do programa institucional de bolsa de iniciação à docência (PIBID). São Paulo: FCC/SEP, 2014.

Governo quer reduzir os recursos do Sistema S.

Disponível em: https://www.bancariosbahia.org.br/noticia/29737,governoquer-reduzir-os-recursos-do-sistema-s.html. Acesso em: 05 out. 2020.

CENSO da Educação Superior. 2018. Disponível em:

http://portal.inep.gov.br/web/guest/educacao-superior. Acesso em: 8 mai. 2020.

JAPIASSU, H.; MARCONDES, D. Dicionário básico de filosofia. 3. ed. Rio de Janeiro: Jorge Zahar, 2001.

MARX, K.; ENGELS, F. Textos sobre educação e ensino. Trad. Rubens Eduardo Frias. São Paulo: Centauro, 2004.

MINISTÉRIO DA EDUCAÇÃO. Disponível em:

http://portal.mec.gov.br/reuni-sp-93318841. Acesso em: 05 out. 2020.

MERCADANTE, A.; ZERO, M. (orgs.). Governos do PT: Um legado para o futuro. São Paulo: Fundação Perseu Abramo, 2018. 
NEZ, E. de.; MOROSINI, M. C. Programa institucional de internacionalização (PRINT): análises frente a uma pandemia. Debates em educação, v. 12, p. 77 - 94, 2020. DOI: https://doi.org/10.28998/21756600.2020v12n28p77-94.

O NACIONAL. 2016. Disponível em:

https://www.onacional.com.br/politica,8/2020/07/24/temer-assumepresidencia-em-def,72297. Acesso em: 29 jul. 2020.

PARTIDO DOS TRABALHADORES (PT). Os governos do PT fizeram uma verdadeira revolução na educação do Brasil. Disponível em:

https://lula.com.br/os-governos-do-pt-fizeram-uma-verdadeira-revolucao-naeducacao-do-brasil/. Acesso em: 15 jun. 2020.

PLACCO, V. M. N. S.; SILVA, Sylvia Helena Souza da. A formação do professor: reflexões, desafios, perspectivas. In: BRUNO, Eliane Bambini; ALMEIDA, Laurinda Ramalho; CHRISTOV, Luíza Helena da Silva (org). $O$ coordenador pedagógico e a formação docente. São Paulo: Edições Loyola, 2009.

PROUNI. Disponível em: http://prouniportal.mec.gov.br/. Acesso em: 05 out. 2020.

SADER, E.; GARCIA, M. A. Brasil entre o passado e o futuro. São Paulo: Boitempo, 2010.

SANTOS. L. G. dos. Tecnologia, perda do humano e crise do sujeito do direito. In: OLIVEIRA, F. de ; PAOLI, M. C. Os sentidos da democracia: politicas do dissenso e hegemonia global. Petrópolis: Vozes: 1999.

SAVIANI, D. Educação brasileira: estrutura e sistema. 10. ed. Campinas: Autores Associados, 2008.

SAVIANI, D. Sistema de ensino e planos de educação: o âmbito dos municípios. Educação e sociedade, a. XX, n. 69, dez. 1999.

SOUZA, J. A elite do atraso da escravidão a lavo jato. Rio de Janeiro: Leya, 2017.

SOUZA, W. C.; NEZ. E. Diálogos entre universidade e educação básica: o PIBID como interlocução na formação de professores. Educação, cultura e sociedade. Sinop, v. 10, n. 1, p. 66-79, jan./jun.2020.

TODOS PELA EDUCAÇÃO. Disponível em:

https://www.todospelaeducacao.org.br/conteudo/O-que-e-um-sistemanacional-de-Educacao. Acesso em: 21 set. 2020. 